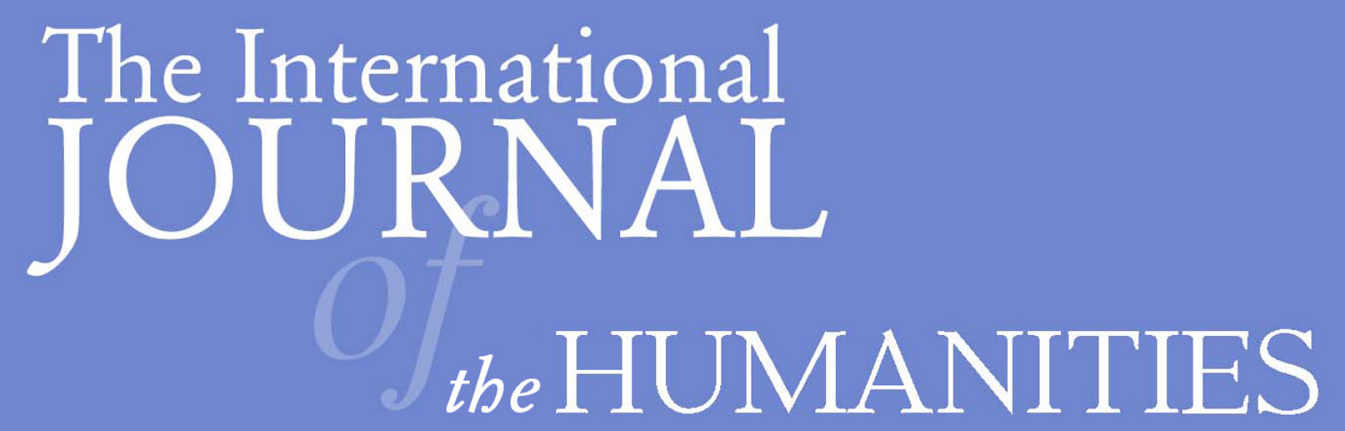

Reasoning about Assassinations

James Fetzer 
INTERNATIONAL JOURNAL OF THE HUMANITIES

http://www.Humanities-Journal.com

First published in 2005/2006 in Melbourne, Australia by Common Ground Publishing Pty Ltd www.CommonGroundPublishing.com.

C) 2005/2006 (this paper), the author(s)

(C) 2005/2006 (selection and editorial matter) Common Ground

Authors are responsible for the accuracy of citations, quotations, diagrams, tables and maps.

All rights reserved. Apart from fair use for the purposes of study, research, criticism or review as permitted under the Copyright Act (Australia), no part of this work may be reproduced without written permission from the publisher. For permissions and other inquiries, please contact <cg-support@commongroundpublishing.com>.

ISSN: 1447-9508 (print), 1447-9559 (online)

Publisher Site: http://www.Humanities-Journal.com

The INTERNATIONAL JOURNAL OF THE HUMANITIES is a peer refereed journal. Full papers submitted for publication are refereed by Associate Editors through anonymous referee processes.

Typeset in Common Ground Markup Language using CGCreator multichannel typesetting system http://www.CommonGroundSoftware.com. 


\title{
Reasoning about Assassinations
}

\author{
Critical Thinking in Political Contexts \\ James Fetzer, University of Minnesota Duluth, United States of America
}

\begin{abstract}
The application of logic, critical thinking, and principles of scientific reasoning, involving collaboration between physicians, scientists, photographic analysts, and philosophers has transformed our knowledge of the death of JFK. Since 1992, a research group I organized has discovered that the autopsy X-rays have been altered, that someone else's brain has been substituted, that a home movie of the assassination has been recreated, and that the alleged assassin, Lee Oswald, was framed using manufactured evidence. This approach, which may be called "assassination science", benefits from applying the pattern of reasoning known as "inference to the best explanation" to important and controversial deaths, where political motivation may have contributing to bringing them about. By focusing on the "best evidence" — the autopsy Xrays, the autopsy report and photographs, the physical evidence (including the alleged assassination weapon), and other crucial evidence - we have undertaken a reconstruction of the case from the most basic evidence up, with special consideration for separating the authentic from the inauthentic evidence. When that has been accomplished, it becomes relatively straightforward to draw appropriate inferences, since the Mafia, for example, would not have been able to extend its reach into Bethesda Naval Hospital to alter X-rays under control of the Secret Service, medical officers of the US Navy, or the President's personal physician; neither pro- nor anti-Castro Cubans could have substituted someone else's brain for that of JFK; even though the KGB might have had the same ability to recreate a film as the CIA, it could not have gained its possession; nor could any of these things have been done by Lee Oswald, who was either incarcerated or already dead. As a novel area of application that might be viewed as "applied philosophical research", assassination science is establishing that the humanities in this new guise can make more than an incidental contribution to the solution of important mysteries in history.
\end{abstract}

Keywords: logic, critical thinking, scientific reasoning, philosophy of science, applied philosophical research, the death of JFK, resolving mysteries in history, historical research, "assassination science"

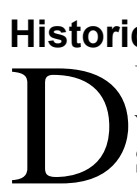

$\mathrm{D}$ lysts, and attorneys to investigate the assassination of President John F. Kennedy (Fetzer 1998). Some, like Jack White, had been long-time students of the case. Others, such as David W. Mantik, M.D., Ph.D., were, like myself, relatively new. Our objective was to take rumor, speculation, and politics out of the case and place its study on an objective and scientific foundation. Eventually, this would lead to a reconstruction of the case from the ground up, where the medical evidence, especially, turned out to hold the key to a meticulous cover-up that was intended to conceal the true causes of the death of JFK. It would include the fabrication and alteration of evidence of several different kinds. Exposing the cover-up would implicate elements of the U.S. government in the crime.

It was surprising to me to discover that there was a superabundance of evidence in this case, much of which was inconsistent and contradictory (Fetzer 2000, 2003) The task would not be easy, since it would require distinguishing the authentic from the inauthentic evidence, something that even official "reinvestigations" of the case, such as the inquiry by the House Select Committee on Assassinations (HSCA), held during 1977-78, had not adequately undertaken. Indeed, confronted with inconsistencies between the testimony of a massive blow-out to the back of the head from more than forty eyewitnesses - from Dealey Plaza, where the shooting occurred; from Parkland Hospital, where President was first treated; and from Bethesda Naval Hospital, where his autopsy was performed - and the government's official account, the HSCA deferred to the autopsy X-rays, which did not show one. It would turn out, however, that the X-rays themselves had been altered to conceal the blow-out to the head (Fetzer 1998).

My background as philosopher of science who was also a former commissioned officer in the Marine Corps may have placed me in an appropriate position to pursue a case of this kind. My research had led me to the elaboration of the principles of inference to the best explanation as the most defensible conception of scientific method, where an hypothesis hi is preferable to an alternative hj, given the avail-

INTERNATIONAL JOURNAL OF THE HUMANITIES, VOLUME 3, 2005/2006

http://www.Humanities-Journal.com, ISSN 1447-9508 (print), 1447-9559 (online)

(C) Common Ground, James Fetzer, All Rights Reserved, Permissions: cg-support@commongroundpublishing.com 
able evidence e, when hi affords "a better explanation" for e than does hj. Likelihood measures are used to evaluate explanatory power, where the likelihood of an hypothesis, given evidence e, is equal to the probability of e if $\mathrm{h}$ were true (Fetzer 1981, 1990, 2002a). Those that are inconsistent with the evidence are tentatively excluded, with the understanding that they may subsequently be revived with changes in the available evidence. The preferable explanation becomes acceptable as the evidence becomes stable or "settles down". Our discoveries about the medical evidence illustrate the application of this approach and the importance of basing conclusions upon all the available evidence.

\section{The Official Account}

According to the FBI and the Secret Service, JFK was killed by three shots fired from above and behind by a lone, demented gunman named Lee Harvey Oswald. One shot hit JFK in the back, another hit Governor John Connally in the back, and the third hit JFK in the head and killed him. That scenario was the government's official position until it turned out that a distant bystander, James Tague, had been hit by a fragment from a shot that had missed. Since the evidence of Tague's injury was indisputable, the investigative board that President Lyndon Johnson had created, commonly called "The Warren Commission", had to account for all the wounds in JFK and Connally on the basis of just two shots. A solution to this problem was devised by Arlen Specter, a commission staff member, which has come to be known as the "magic bullet" theory.

JFK had a wound to the throat and another to his back and at least one wound to his head. Connally had an entry wound in his back, a broken rib, an exit wound in his chest, a wound to his right wrist, and a bullet fragment embedded in his left thigh. According to what would become "the official account", most of these wounds were caused by a single bullet that entered the base of the back of the President's neck, transited his neck without hitting any bony structures, exited his throat right at the knot of his tie, entered John Connally's back, shattering a rib, exiting from his chest, damaging his right wrist and then entering his left thigh, where the bullet alleged to have performed these feats was nevertheless found in virtually pristine condition. The other shot that found its mark was said to have hit JFK's head and killed him.

When the official account, which is usually referred to as The Warren Report (1964), appeared, many readers were fascinated to discover that, no matter how implausible it might appear, the "magic bullet" hypothesis was the core of the government's case. And that has remained true through subsequent reinvestigations of the assassination by the House Select Committee on Assassinations during 197678 , and in more recent books, such as Gerald Posner, Case Closed (1993). So if the "magic bullet" hypothesis is false, then there had to be other shots and other shooters and The Warren Report (1964), The HSCA Final Report (1979), and Case Closed (1963) cannot be true. One of our tasks would be to evaluate evidence for and against the "magic bullet" hypothesis, some of which had been known from the very early stages of investigation of the case but whose logical force deserved further analysis and consideration (Fetzer 2002b)
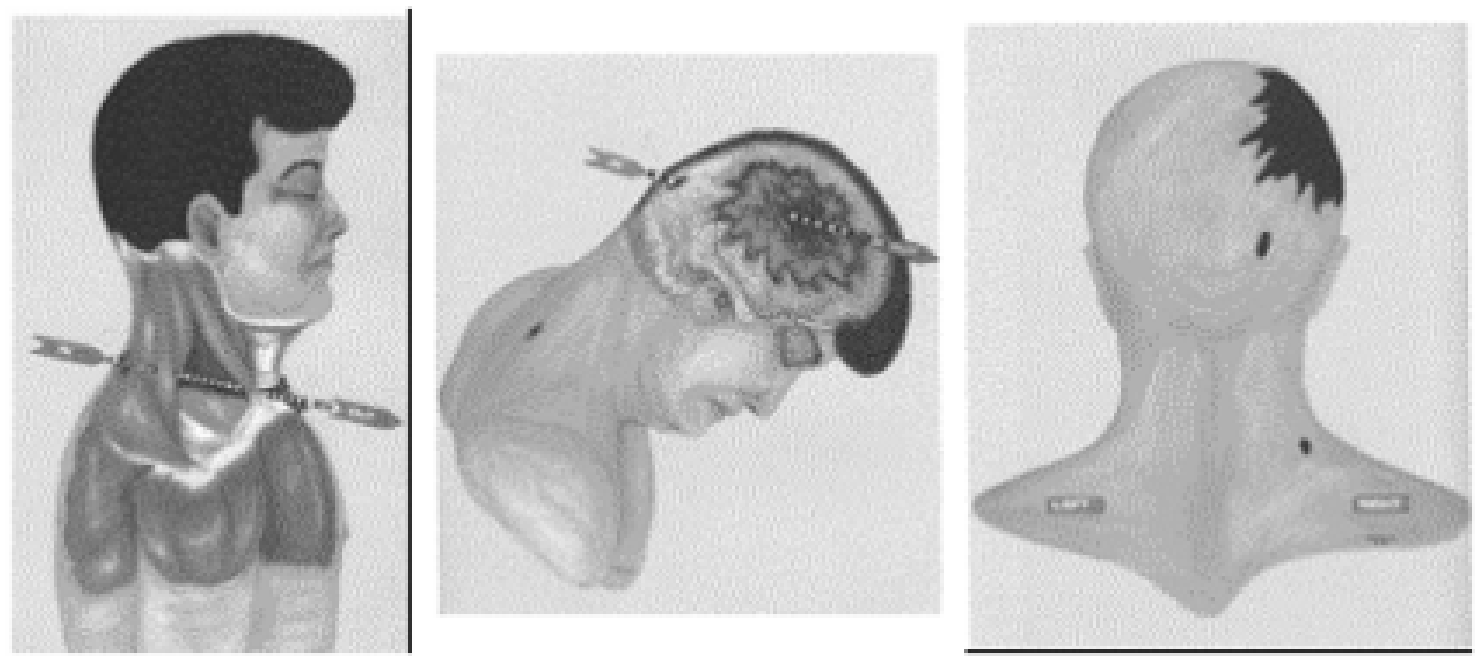

Figure 1: Warren Commission Diagrams of JFK's Wounds 


\section{The "Magic Bullet" Hypothesis}

The Warren Report (1964) published diagrams of the injuries that the President had purportedly sustained, which displayed a hit to the base of the back of the neck and a hit to the back of the head, which is the wound that allegedly killed him (Figure 1). The "magic bullet" theory would be false if the bullet had not entered the base of the back of the President's neck, if it had not transited his neck without hitting any bony structures, or if it had not exited from his neck at the level of the knot of his tie, as the official account maintains. The Navy physicians who conducted the autopsy at Bethesda did not actually dissect the neck to determine the trajectory this bullet is supposed to have taken but ascertained it as a matter of "inference". Thus, page 4 of the autopsy report includes following claim (Assassination Science 1998, page 433):

The second wound presumably of entry is that described above in the upper right posterior thorax. ... The missile path through the fascia and musculature cannot be easily probed. The wound presumably of exit was that described by Dr. Malcolm Perry in the low anterior cervical region.

Notice, in particular, that the entry and exit locations were matters of "presumption", which Commander James Humes, U.S. Navy Medical Corps, defended on the basis of an "inference" drawn after the body had been removed from the morgue for preparation for burial and the official state funeral. Based upon conversations with Parkland that allegedly only took place on Saturday, after the body had been removed, he (Humes) belatedly realized that the wound to the back must have been the entry point for the wound to the throat as its point of exit! Notice too that the description of "the upper right posterior thorax", which is the upper-right portion of the chest cavity, does not quite place the wound where it has to be if the "magic bullet" hypothesis were true. Posner's diagram from Case Closed (Figure 2) likewise does not accord with Figure 1.

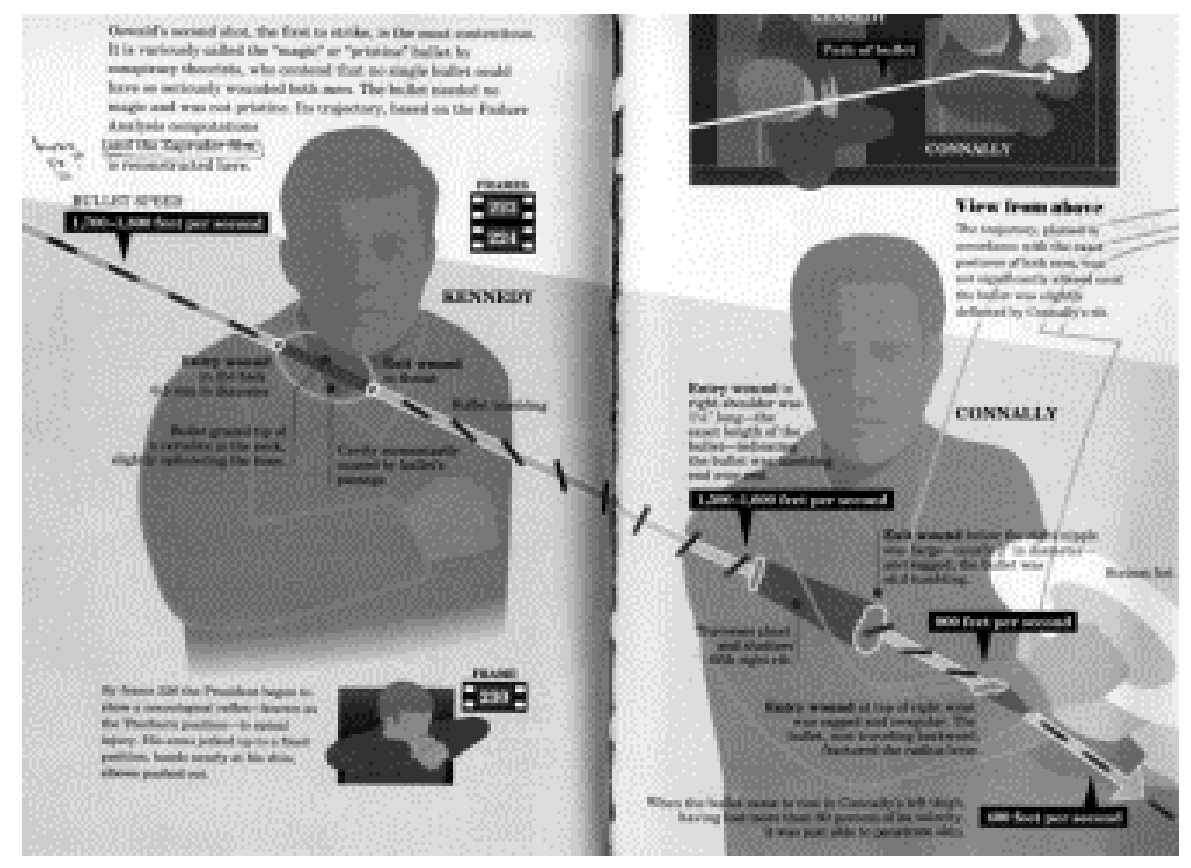

Figure 2: Gerald Posner's Depiction of the "Magic Bullet" Theory

\section{Contradictory Evidence}

There turns out to be extensive evidence that bears upon the question of where the bullet that hit JFK in the back actually impacted with his body, including damage to the shirt and the jacket he was wearing at the time. Many books, including Josiah Thompson, Six Seconds in Dallas (1967), and Gary Shaw and Larry Harris, Cover-Up (1976/1992), have noted that holes in the shirt and the jacket suggest that the entry point was actually about $51 / 2$ inches below the collar. Photographs of the shirt and jacket may be found, for example, in Thompson (1967), page 48, and in Shaw and Harris (1976/ 1992), page 64, as well as in other sources, including Stewart Galanor, CoverUp (1998), Documents 6 and 7 (Figure 3). That the shirt and the jacket might have been "bunched" has been proposed to explain away this anomaly. (See Figure 6 below.) 
That holes in his clothing at a location $51 / 2$ inches below the collar could have been caused by "bunching" becomes less and less plausible as more and more evidence of the wound on the body becomes available. Neither Humes himself, who conducted the autopsy, nor Lt. Commander J. Thornton Boswell, USNMC, who assisted him, had ever performed an autopsy on a gunshot victim before.

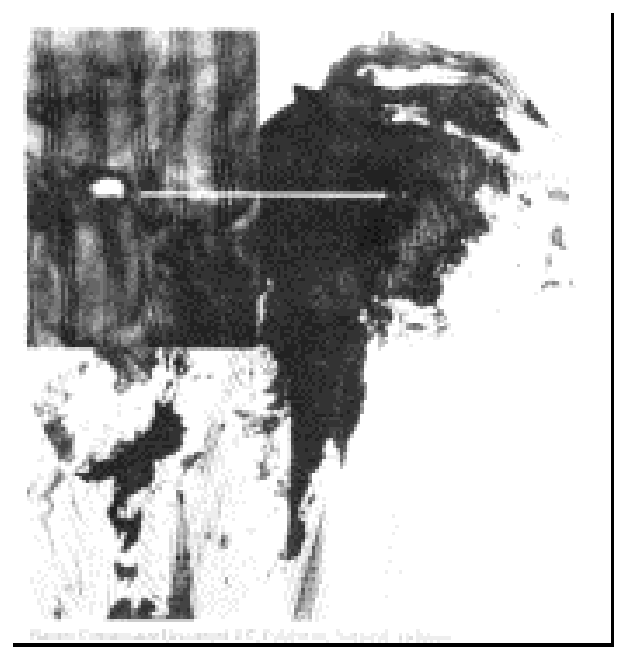

Boswell, however, prepared a diagram of various wounds they observed on the body during the autopsy, which was subsequently verified by Admiral George G. Burkley, USNMC, the President's personal physician. Copies of Boswell's diagram can be found in Shaw and Harris (1976/1992), page 62, and in Galanor (1998), Document 5, and Fetzer (2000), page 230 (Figure 4).

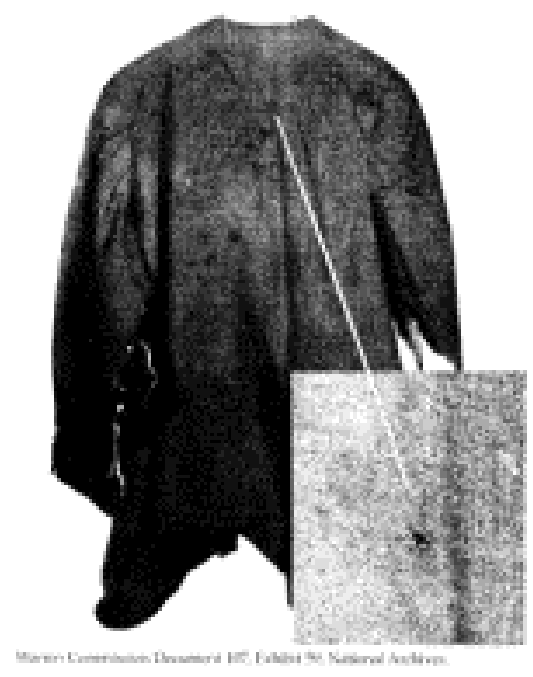

Figure 3: Photographs of the President's Shirt and Jacket

A different diagram was prepared by FBI Agent James W. Sibert, who observed the autopsy at Bethesda, which may be found in Noel Twyman, Bloody Treason (1997), page 100. It plainly demonstrates the difficulties confronted by the "magic bullet" hy- pothesis, even in relation to its most elementary assumptions, since the wound to the back is too low to be the entry point for a wound that exited from the throat, if the bullet was fired from above and behind, as the official account claims (Figure 5).
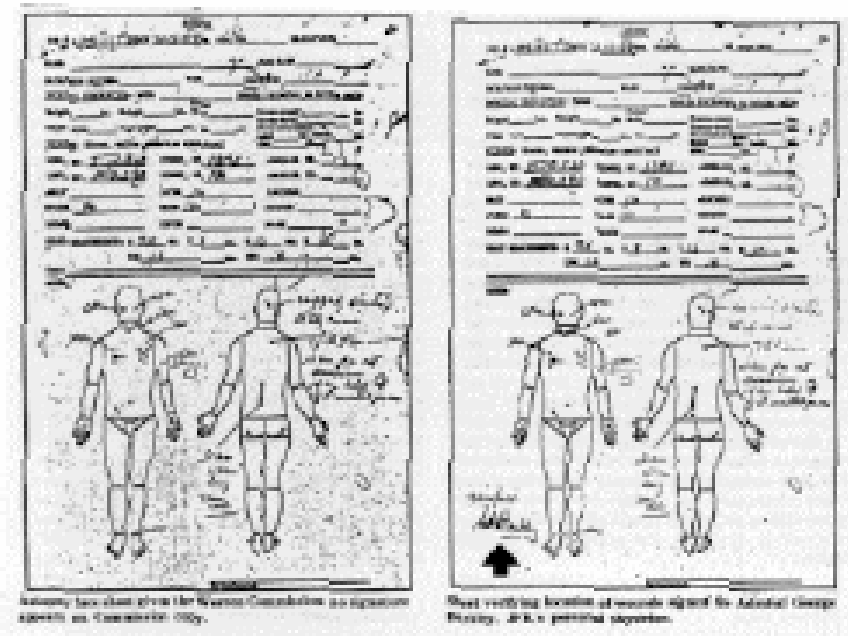

Figure 4: Boswell's Autopsy Diagram, Verified by Burkley 


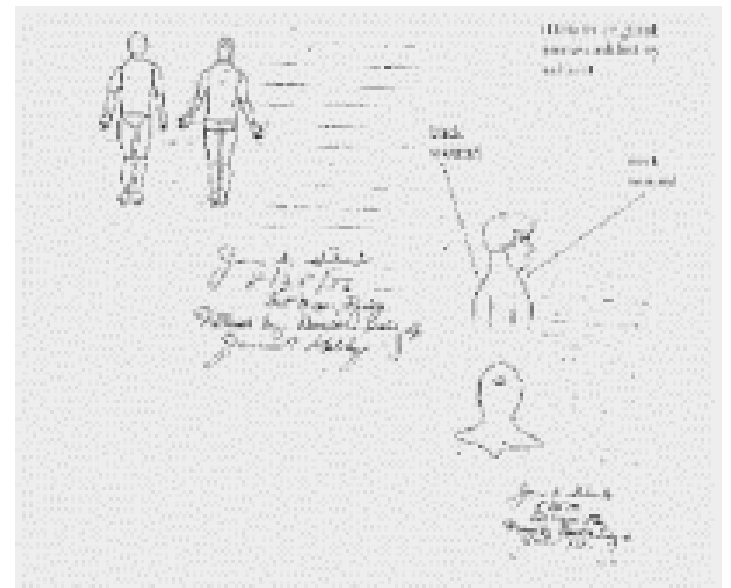

Figure 5: Agent Sibert's Diagram of the Location of the Wounds

\section{Evaluating the Evidence}

The application of inference to the best explanation tends to clarify and illuminate the significance of the available evidence in relation to alternative hypotheses. According to the official account, h1, the bullet hit the President at the base of the back of the neck, as the "magic bullet" hypothesis requires. If h1 were true, then probability of holes in the shirt and jacket about $51 / 2$ inches below the collar would be low, but not impossible if, for example, they had been "bunched". But the probability that the shirt and jacket were "bunched", when diagrams of the wounds on the body also show the wound about 5 $1 / 2$ inches below the collar, is extremely low. Interestingly, the artist who prepared the official diagrams (Figure 1) was not even allowed to actually view the body. And the shirt and the jacket, which were removed from the body at Parkland, were not transported to Bethesda for the autopsy physicians to study them.

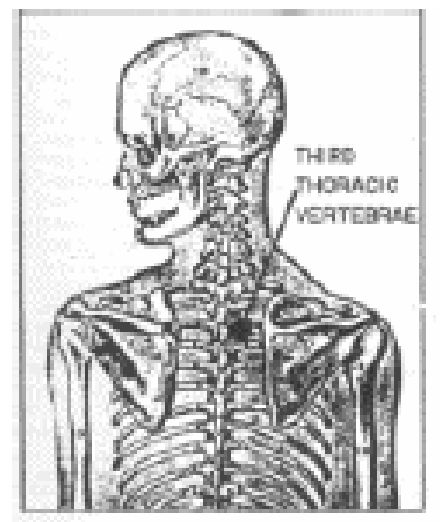

Figure 6: The Location of the Third Thoracic Vertebra

Moreover, Sibert attended the autopsy with a second FBI agent, Francis X. O'Neill, subsequently submitting a report of their observations at the time on 9

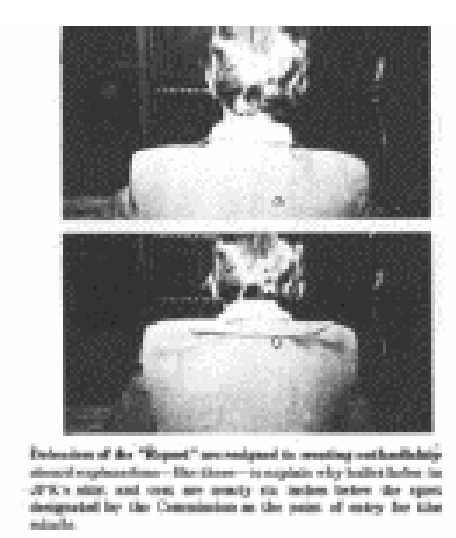

The probability that there would be holes in the shirt and the jacket corresponding to the location of the wounds described in the Boswell and the Sibert diagrams would be very high, if the hypothesis, h2, that JFK was hit about $51 / 2$ inches below the collar, were true. The bunching conjecture tends to be disconfirmed by these two diagrams. Indeed, as more and more evidence is taken into account, support for h1 diminishes and support for h2 increases. The President's physician, Admiral Burkley, executed a death certificate, which may be found in Shaw and Harris (1976/1992), page 65, in Galanor (1998), Document 8, and in Fetzer (1998), page 439. According to Burkley, he was killed by a shot to the head, but "a second wound occurred in the posterior back at about the level of the third thoracic vertebra." The third thoracic vertebra turns out to be much too low to have been the entry for any bullet fired from above and behind that could possibly have exited from the President's throat at the level of the knot of his tie, as Shaw and Harris (1976/1992), page 65, have explained (Figure 6). 
his shoulder to the right of the spinal column at an angle of 45 to 60 degrees downward, that there was no point of exit, and that the bullet was not in the body." An excerpt of their report, including this passage, may be found in Mark Lane, Rush to Judgment (1966), Appendix IV, and is also discussed by Robert Groden, The Killing of a President (1993), pages 78-79. Sibert and O'Neill substantiate that the wound was at a downward angle, that there was no point of exit, and that the bullet was not in the body, which decreases the likelihood of the "magic bullet" hypothesis, h1, and increases the likelihood of h2.

\section{Acceptance and Rejection}

That $\mathrm{h} 2$ is preferable to $\mathrm{h} 1$, given the available evidence, does not imply that it is also acceptable.
That depends on whether the evidence available is sufficient to support it, which requires that it has "settled down". Other evidence supports the inference that the evidence has settled down, including reconstruction photographs that were taken during the reenactment conducted by the Warren Commission staff. A photograph of the re-enactment, for example, that may be found in Galanor (1997), as Document 4 , shows a small round patch at the base of the back of the head marking the location of the head shot and a larger round white patch about $51 / 2$ inches below the collar to mark the back shot. A similar

photograph appears on the inside front cover of The New York Times paperback (1964), that contradicts the official account (Figure 7).

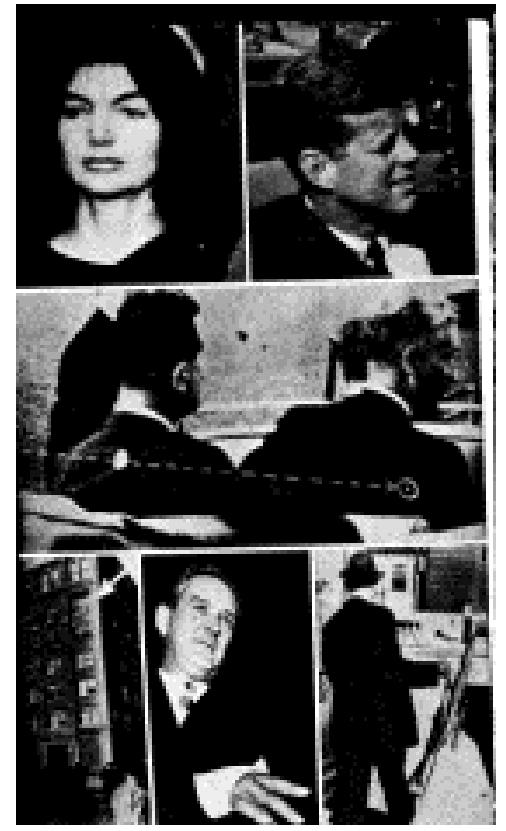

Figure 7: New York Times' re-Enactment Photographs

Readers who are unfamiliar with this case may wonder how in the world, given all of this evidence, The Warren Report (1964) could have concluded that JFK was hit at the base of the back of the neck. Thanks to the good work of the Assassination Records Review Board (ARRB), a five-member civilian board authorized to declassify records and documents held by the CIA, the FBI, the Secret Service, and other agencies, we know the answer to that question. Gerald Ford, a member of the commission, had the description of the wound changed from "his uppermost back", which was already an exaggeration, to "the back of his neck", a discovery that was among the very first of the ARRB's important releases, which came in time for me to include an article about it from The New York Times (3 July 1997), page 8A, in Fetzer (1998), on page 177.
Under these circumstances, it almost appears to be "piling on" to note that David W. Mantik, M.D., Ph.D., has recently demonstrated that no bullet could have entered the President's neck at the location alleged and exited at the location alleged without impacting cervical vertebrae, as Galanor (1998), Document 45, and as Fetzer (2000), pages 3-4, explain (Figure 8). Nor does it even seem necessary to add that Malcolm Perry, M.D., who performed a tracheostomy in a vain attempt to save the President's life, described the wound to the throat not as an exit wound, but as an entry wound, three times during a press conference at Parkland that began at 3:16 PM, a report widely broadcast over radio and television that day. No transcript would be given to the Warren Commission on the ground that it was too difficult to locate, but a copy of the complete press conference transcript now appears in Fetzer (1998) as Appendix C. 


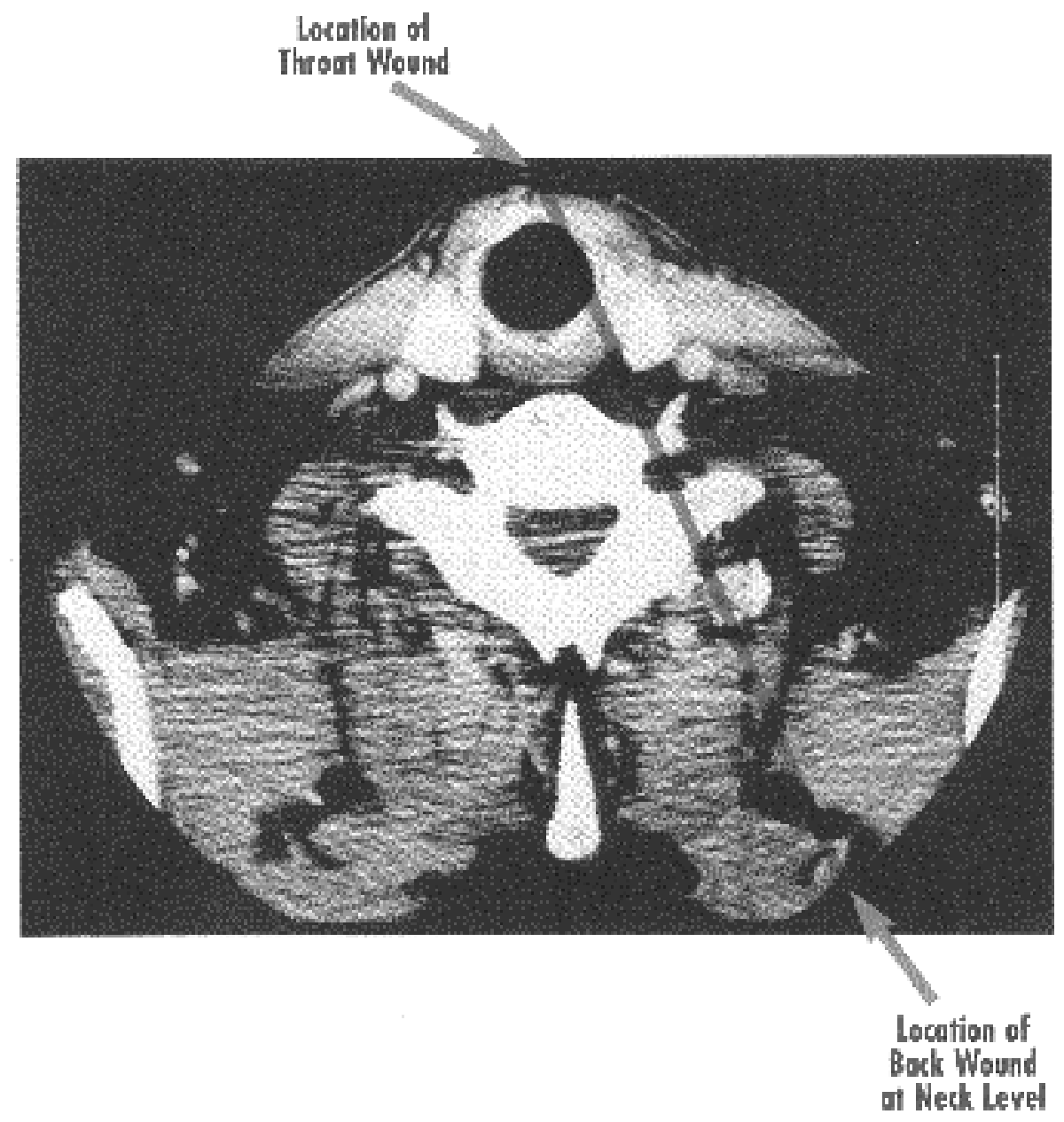

Figure 8: Mantik Plotted the Trajectory on a CAT Scan

\section{Logical Ramifications}

It may come as some surprise that the seemingly simple question, "Where did the bullet that hit the President in the back enter?", should hold the key to exposing the cover-up in the assassination of JFK. Because if it was not at the base of the back of the neck as the "magic bullet" hypothesis requires, then The Warren Report (1964), The HSCA Report (1979), Case Closed (1993), and every other work that takes it for granted cannot possibly be true. The probability of the evidence we have reviewed here-including the holes in the shirt and jacket, the wounds depicted in the Boswell and Sibert diagrams, Burkley's and Sibert and O'Neill's descriptions of the wound, and the reenactment photographs - has a value that is approximately zero, relative to the official account. Indeed, Mantik has proven that it is not even anatomically possible. The probability of the same evidence, assuming that JFK was hit about $51 / 2$ inches below the collar, by comparison, is very, very high. The evidence has "settled down".
Given the discovery by the ARRB that Gerald Ford had the wound redescribed in The Warren Report (1964) — no doubt to make the "magic bullet" theory more plausible - and that Mantik has determined that no bullet could have taken such a trajectory, it turns out that the core of the official account is not only false but provably false and not even anatomically possible! It follows that JFK's throat wound and the wounds to John Connally had to have been caused by separate shots and separate shooters and could not have been inflicted by a lone assassin firing from above and behind. The truth would have been glaring but for suppressing evidence by not sending the shirt and jacket to Bethesda for the physicians to study, by not providing transcripts of the Parkland Press Conference to the Warren Commission and using similar techniques. Indeed, the process of selection and elimination-selecting evidence that supports a predetermined conclusion and eliminating the rest - is well-known to all of those who practice 
propaganda and specialize in misleading the public

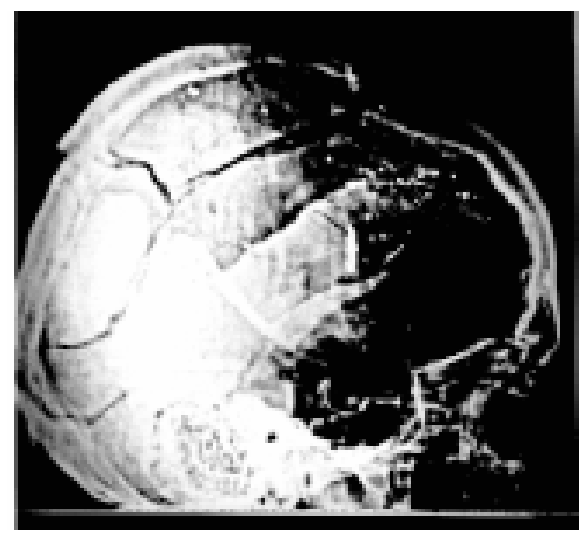

in the search for truth.

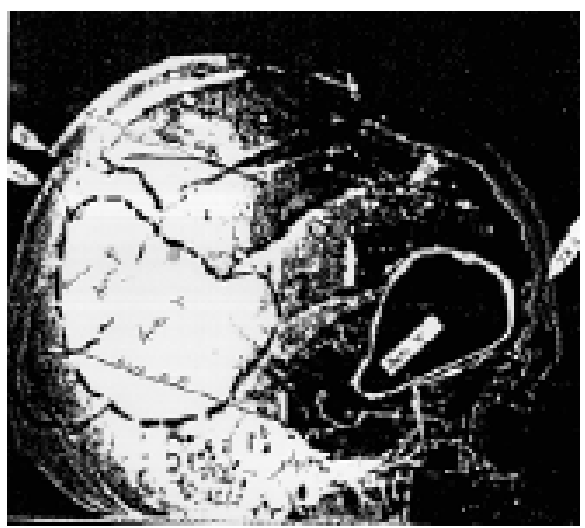

Figure 9: Mantik's Study of the Lateral Cranial AUTOPSY X-ray

Our research has not only falsified the "magic bullet" hypothesis and thereby exposed the fraud at the foundation of the government's official account but has also led to the discovery of complementary deceptions in the death of JFK. The most important are that the autopsy X-rays have been fabricated (a) to conceal the massive blow-out to the back of the head that more than forty eyewitnesses reported and (b) to add a $6.5 \mathrm{~mm}$ metallic slice in an apparent effort to implicate an obscure World War II Italian Mannlicher-Carcano as the weapon used (Figure 9). A world authority on the human brain, Robert B. Livingston, M.D., has concluded that the brain shown in diagrams and photographs held in the National Archives cannot possibly be the brain of JFK. These discoveries had already been made by 1993 (Fetzer 1998). In spite of our repeated efforts to bring these findings to the attention of the American people (through "ABC Nightly News" and "Nightline") and the Department of Justice, we had slight success.

\section{Where We Stand Today}

On the basis of our extended research, we have established that JFK was hit at least four times: once in the throat from in front; once in the back from behind; and twice in the head, once from the back and once from in front; and that Connally was hit from one to three times, where at least three shots seem to have missed. A total of eight, nine, or ten shots appear to have been fired from six different locations (Fetzer 2000, 2003). As a striking example of how official inquiries by the government have suppressed or overlooked important evidence, Thomas Evan Robinson, the mortician who prepared the body for burial after the Bethesda autopsy, told Joe West, a private investigator, that JFK had a large gaping hole in the back of his head, a smaller wound in the right temple (which was the entry wound for the blow-out to the back of the head), and a wound to the back about five to six inches below the shoulder and to the right of the back bone. He provided this information to West on 26 May 1992, but it obviously could have been available to the Warren Commission if it had wanted it (Figure 10).

In collaboration with other experts, including John P. Costella, Ph.D., we have also discovered that the home movie of the assassination, known as "the Zapruder film", has been recreated using sophisticated techniques of optical printing and special effects. Because of "ghost images" that link successive frames, it was necessary to reshoot the film in order that the deception not be easily exposed (Fetzer 2003). We have also discovered more than fifteen indications of Secret Service complicity in setting JFK up for the hit, including failing to weld manhole covers, failure to cover open windows, allowing the crowd to spill over into the street, adopting an improper motorcade route, ordering the vehicles in the wrong sequence, keeping motorcycle patrolmen to the rear of the limousine, bringing the limousine to a halt after bullets began to be fired, washing blood and brains from the limousine at Parkland, taking the autopsy photographs and X-rays from the physicians prior to completing their work, having the limousine stripped down and completely rebuilt. The probability that these things happened "by chance" is vanishingly small (Fetzer 2000, 2002a).

The conclusions that can be drawn from the authentic evidence are rather profound. The Mafia, which may have put up some of the shooters for the assassination, could not have extended its reach into Bethesda Naval Hospital to alter X-rays under the control of U.S. Navy medical officers, agents of the Secret Service, or the President's personal physician. Neither pro- nor anti-Castro Cubans could have substituted the brain of someone else for that of JFK during a supplemental autopsy. And even if the KGB, like the CIA, had the ability to recreate a film, it could not have obtained a copy of the Zapruder film 
to alter it. Nor could any of these things have been done by Lee Harvey Oswald, who was incarcerated or already dead. Similar reasoning based upon the application of inference to the best explanation, alas!, leaves no reasonable doubt that setting up JFK for the hit and altering the evidence to conceal the true causes of his death must have involved elements at the highest levels of the U.S. government.

Thomas Euan Robincon

ADDRESS AND PHONE INFORMATION DELETED FOR MR. ROBINSON'S PRIVACY

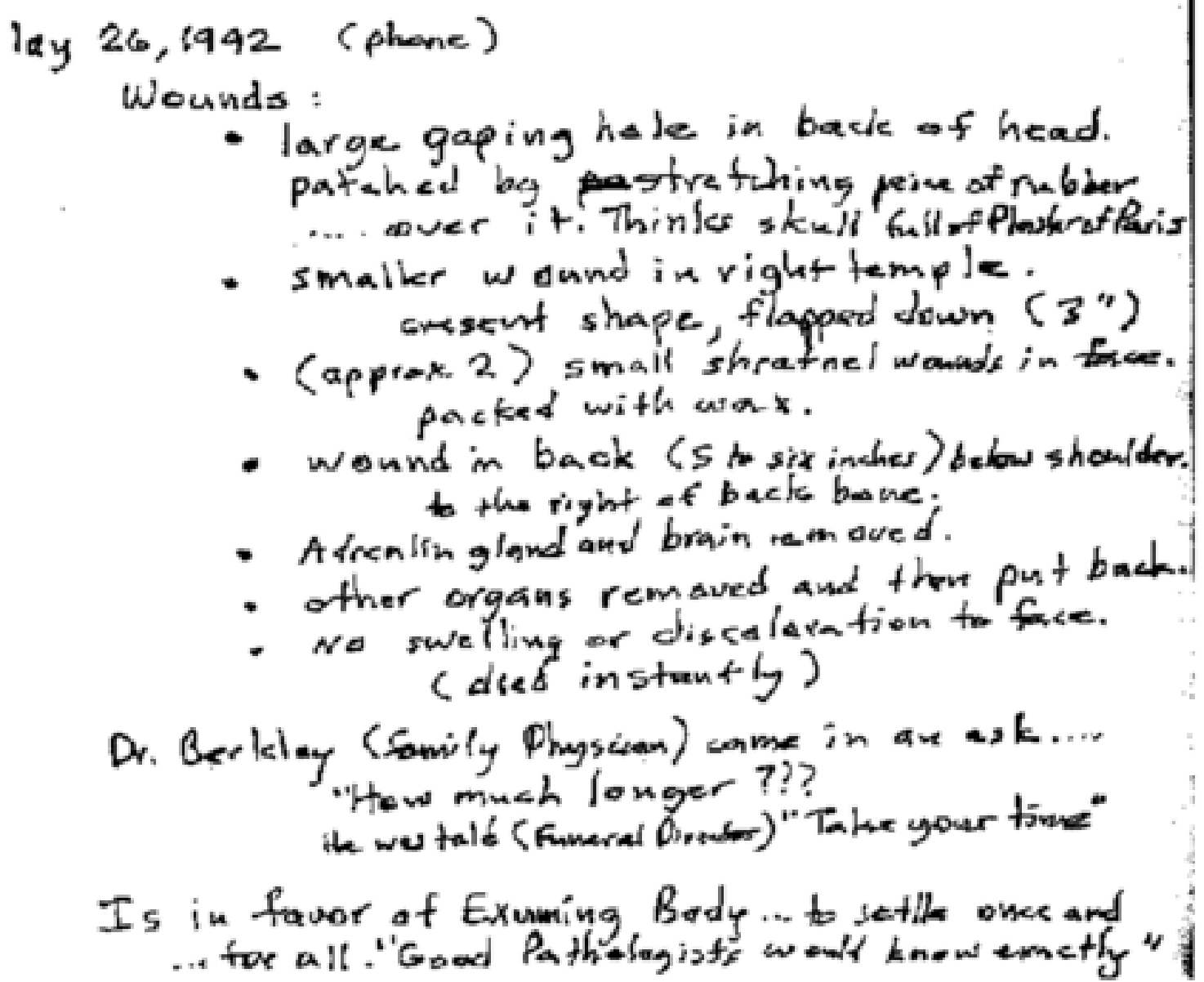

Figure 10: Summary of Interview with Thomas Evan Robinson

\section{References}

Fetzer, James H. Scientific Knowledge: Causation, Explanation, and Corroboration. Dordrecht, Holland: D. Reidel, 1981. Philosophy of Science. New York, NY: Paragon House, 1993.

, ed. Assassination Science: Experts Speak Out on the Death of JFK. Chicago, IL: Open Court, 1998.

Murder in Dealey Plaza: What we Know Now that we Didn't Know Then about the Death of JFK. Chicago, IL: Open Court, 2000.

"Propensities and Frequencies: Inference to the Best Explanation". Synthese 132/1-2 (July/August 2002a), pp. $27-$ 61.

. "The 'Lone-Nutter' Refutation" (2002b). This electronic piece appears on-line at http://assassinationresearch.com/v1n1/lonenutter.html.

The Great Zapruder Film Hoax: Deceit and Deception in the Death of JFK. Chicago, IL: Open Court, 2003. Galanor, S. Cover-Up. New York, NY: Kestrel Books, 1998.

Groden, R. The Killing of a President. New York, NY: Penguin Books, 1993.

Lane, M. Rush to Judgment. New York, NY: Thunder's Mouth Press, 1966.

Posner, G. Case Closed: Lee Harvey Oswald and the Assassination of JFK. New York, NY: Random House, 1993. 
Shaw, G., and L. Harris. Cover-Up.: The Governmental Conspiracy to Conceal the Facts about the Public Execution of John Kennedy. Thomas Investigative, 1976/2nd ed., 1992.

Stokes L., et al. Report of the House Select Committee on Assassinations. New York, NY: Bantam Books, 1979.

Thompson, J. Six Seconds in Dallas: A Micro-Study of the Kennedy Assassination. New York, NY: Bernard Geis Associates, 1967.

Twyman, N. Bloody Treason: On Solving History's Greatest Murder Mystery. Rancho Santa Fe, CA: Laurel Publishing, 1997.

Warren, E., et al. Report of the President's Commission on the Death of President Kennedy. New York, NY: St. Martin's Press, 1964

Warren, E., et al. Report of the President's Commission on the Death of President Kennedy. New York, NY: New York Times/Bantam Books, 1964.

\section{About the Author}

\section{Dr. James Fetzer}

James H. Fetzer, Distinguished McKnight Professor of Philosophy at the University of Minnesota, who teaches on its Duluth campus, has published more than 20 books in the philosophy of science and on the theoretical foundations of computer science, artificial intelligence, and cognitive science. He received his Ph.D. in the history and philosophy of science from Indiana in 1970. His new study, "The Evolution of Intelligence: Are Humans the Only Animals with Minds?" (forthcoming), integrates his earlier research on the differences between thinking things and digital machines with his recent research on human and animal mentality. He has edited three books on the death of "JFK, Assassination Science" (1998), "Murder in Dealey Plaza" (2000), and "The Great Zapruder Film Hoax" (2003), and has co-authored a fourth — "American Assassination" (2004) — on the death of Senator Paul Wellstone. He is pioneering a novel area of research he has labeled "assassination science", which involves the application of principles of scientific reasoning, especially "inference to the best explanation", to investigate the death of prominent politicians. This is indispensable where there may be reason to suspect they have been assassinated by their own government. Assassination science thus has an essential role to play in evaluating official reports to insure they are not serving the purpose of covering up crimes. His work emphasizes that each case has to be evaluated by the rigorous application of appropriate principles of logic, critical thinking, and scientific reasoning to all the available relevant evidence. And it demonstrates the practical significance of philosophical explications. 


\section{THE INTERNATIONAL JOURNAL OF THE HUMANITIES}

\section{EDITORS}

Tom Nairn, RMIT University, Melbourne.

Mary Kalantzis, RMIT University, Australia.

\section{EDITORIAL ADVISORY BOARD}

Fethi Mansouri, Deakin University, Melbourne, Australia.

Paul James, RMIT University, Australia.

Juliet Mitchell, Cambridge University, UK.

Siva Vaidhyanathan, New York University, USA.

Patrick Baert, Cambridge University, UK.

Ted Honderich, University College, London.

Krishan Kumar, University of Virginia, USA.

David Christian, San Diego State University, California, USA.

Giorgos Tsiakalos, Aristotle University of Thessaloniki, Greece.

Gayatri Chakravorty Spivak, Columbia University, USA.

Mick Dodson, Australian National University, Canberra, Australia.

Jeffrey T. Schnapp, Stanford University, USA.

Nikos Papastergiadis, University of Melbourne, Australia.

Bill Kent, Monash Centre, Prato, Italy.

Chris Ziguras, RMIT University, Australia.

Eleni Karantzola, University of the Aegean, Greece.

Bill Cope, Common Ground, Australia.

ASSOCIATE EDITORS, 2005

Visit: http://www.Humanities-Journal.com

SCOPE AND CONCERNS

Visit: http://www.Humanities-Journal.com

SUBMISSION GUIDELINES

Visit: http://www.Humanities-Journal.com

INQUIRIES

Email: cg-support@commongroundpublishing.com 